\title{
ATF4 Mediates Mitochondrial Unfolded Protein Response in Alveolar Epithelial Cells
}

\author{
Dingyuan Jiang ${ }^{1,2}$, Huachun Cui ${ }^{1}, \mathrm{Na} \mathrm{Xie}^{1}$, Sami Banerjee ${ }^{1}$, Rui-Ming Liu ${ }^{1}$, Huaping Dai ${ }^{2}$, Victor J. Thannickal ${ }^{1 *}$, and \\ Gang Liu ${ }^{1}$
}

${ }^{1}$ Division of Pulmonary, Allergy, and Critical Care Medicine, Department of Medicine, University of Alabama at Birmingham, Birmingham, Alabama; and ${ }^{2}$ Department of Pulmonary and Critical Care Medicine, Center of Respiratory Medicine, China-Japan Friendship Hospital, National Clinical Research Center for Respiratory Diseases, Beijing, China

ORCID ID: 0000-0003-2615-131X (G.L.).

\begin{abstract}
Although endoplasmic reticulum (ER) unfolded protein response $\left(\mathrm{UPR}^{\mathrm{ER}}\right)$ is well known, mitochondrial unfolded protein response $\left(\mathrm{UPR}^{\mathrm{mt}}\right)$ has not been recognized in alveolar epithelial cells. Furthermore, ER stress and mitochondrial dysfunction are frequently encountered in alveolar epithelial cells from an array of lung disorders. However, these two scenarios have been often regarded as separate mechanisms contributing to the pathogeneses. It is unclear whether there is interplay between these two phenomena or an integrator that couples these two signaling cascades in the stressed alveolar epithelial cells from those pathologies. In this study, we defined $\mathrm{UPR}^{\mathrm{mt}}$ in alveolar epithelial cells and identified ATF4 (activating transcription factor 4), but not ATF5, as the key regulator of $\mathrm{UPR}^{\mathrm{mt}}$. We found that $\mathrm{UPR}^{\mathrm{ER}}$ led to $\mathrm{UPR}^{\mathrm{mt}}$ and mitochondrial dysfunction in an ATF4-dependent manner. In contrast, mitochondrial stresses did not activate $U P R^{\mathrm{ER}}$. We found that alveolar epithelial ATF4 and $\mathrm{UPR}^{\mathrm{mt}}$ were induced in aged mice with experimental pulmonary fibrosis as well as in patients with idiopathic pulmonary fibrosis. Finally, we found that the inducible expression of ATF4 in mouse alveolar epithelial cells aggravated pulmonary
\end{abstract}

$\mathrm{UPR}^{\mathrm{mt}}$, lung inflammation, body weight loss, and death upon bleomycin-induced lung injury. In conclusion, ER stress induces ATF4-dependent UPR ${ }^{\mathrm{mt}}$ and mitochondrial dysfunction, indicating a novel mechanism by which ER stress contributes to the pathogeneses of a variety of pulmonary disorders.

Keywords: mitochondrial UPR; alveolar epithelial cell; ER stress; pulmonary fibrosis

\section{Clinical Relevance}

This study defines mitochondrial unfolded protein response $\left(\mathrm{UPR}^{\mathrm{mt}}\right)$ in alveolar epithelial cells and identifies ATF4 as the key regulator of $\mathrm{UPR}^{\mathrm{mt}}$ in these cells. This study also demonstrates that endoplasmic reticulum unfolded protein response induces $\mathrm{UPR}^{\mathrm{mt}}$ and mitochondrial dysfunction, thus providing a previously unappreciated mechanism by which endoplasmic reticulum unfolded protein response contributes to a number of pulmonary pathogeneses.
Unfolded protein response (UPR) is commonly known as an intracellularsignaling cascade triggered by stresses associated with an accumulation of unfolded or misfolded proteins in the endoplasmic reticulum (ER) $\left(\mathrm{UPR}^{\mathrm{ER}}\right)(1,2) . \mathrm{UPR}^{\mathrm{ER}}$ signaling is comprised of three distinct but interconnected arms that act through
PERK, IRE1 $\alpha$, and ATF6, respectively. The ER stress-activated PERK causes eIF2 $\alpha$ (eukaryotic initiation factor $2 \alpha$ ) phosphorylation, which attenuates the

(Received in original form March 23, 2020; accepted in final form June 18, 2020)

*V.J.T. is Associate Editor of AJRCMB. His participation complies with American Thoracic Society requirements for recusal from review and decisions for authored works.

Supported by the U.S. National Institutes of Health grant HL135830 and Department of Defense grant W81XWH-20-1-0226, and National Natural Science Foundation of China grants 81700067 and 81870056.

Author Contributions: D.J. and H.C. contributed equally to this work. D.J., H.C., and G.L. designed the study. D.J., H.C., N.X., S.B., R.-M.L., H.D., and G.L. performed the experiments and/or analyzed the data. D.J., H.C., V.J.T., and G.L. wrote the manuscript.

Correspondence and requests for reprints should be addressed to Gang Liu, M.D., Ph.D., Professor of Medicine, Division of Pulmonary, Allergy, and Critical Care Medicine, Department of Medicine, University of Alabama at Birmingham, 901 19th Street So., BMR II 233, Birmingham, AL 35294. E-mail: gangliu@uabmc.edu.

This article has a related editorial.

This article has a data supplement, which is accessible from this issue's table of contents at www.atsjournals.org.

Am J Respir Cell Mol Biol Vol 63, Iss 4, pp 478-489, Oct 2020

Copyright $\odot 2020$ by the American Thoracic Society

Originally Published in Press as DOI: 10.1165/rcmb.2020-0107OC on June 18, 2020

Internet address: www.atsjournals.org 
global translation to ease protein loading onto the stressed ER (1-3). However, eIF2 $\alpha$ phosphorylation also preferentially enhances the translation of certain genes, including ATF4 (activating transcription factor 4) and ATF5, by a mechanism involving the upstream open reading frames present in their $5^{\prime}$ untranslated regions $(1,3)$. ATF4 and ATF5, both basicleucine zipper domain transcriptional factors, upregulate an arsenal of mediators, such as ER molecular chaperons, to resolve ER stresses. The primary function of $\mathrm{UPR}^{\mathrm{ER}}$ is to restore protein homeostasis in the stressed ER. However, an aberrant or a prolonged activation of UPR ${ }^{\mathrm{ER}}$ has been implicated in a number of pathogeneses, although the underlying mechanism remains incompletely understood (1-4).

In addition to ER stresses, many types of mitochondria stresses also lead to mitochondrial UPR (UPR ${ }^{\mathrm{mt}}$ ) (5). UPR ${ }^{\mathrm{mt}}$ is initially described in Caenorhabditis elegans as an adaptive transcriptional program responding to an impaired mitochondrial proteome (5-7). The C. elegans transcriptional factor ATFS-1 is recognized as a pivotal regulator of UPR ${ }^{\mathrm{mt}}$ because it elevates the expression of mitochondrial chaperons and proteases that promote mitochondrial homeostasis $(5,8)$. $\mathrm{UPR}^{\mathrm{mt}}$ has been subsequently found to also occur in mammalian cells upon exposure mitochondrial insults $(5,9)$. Recent evidence points to the possibility that ATF4, ATF5, and CHOP (C/EBP homologous protein) are the orthologous transcription factors of ATFS-1 in mammals $(5,10,11)$. Although transient mitochondrial stresses and the induction of $\mathrm{UPR}^{\mathrm{mt}}$ seem beneficial in certain pathophysiological settings (12-15), persistent stresses inevitably lead to mitochondrial dysfunction and are a known cause for numerous diseases (16, 17). The regulation and the role of $U P R^{\mathrm{mt}}$ in mammalian cells under these conditions remain ambiguous.

Both ER stresses and mitochondrial dysfunction are frequently experienced in alveolar epithelial cells (AECs) from a range of lung disorders, such as idiopathic pulmonary fibrosis (IPF), acute lung injury, and chronic obstructive pulmonary disease (18-25). However, despite this apparent connection, such cellular undertakings are usually perceived as separate mechanisms contributing to these pathogeneses.

Evidence is lacking on whether there is an interplay between these two phenomena in AECs. It is unknown whether an integration of $\mathrm{UPR}^{\mathrm{ER}}$ and $\mathrm{UPR}^{\mathrm{mt}}$ exists in stressed AECs from these disorders.

In this study, we demonstrated that ATF4, but not ATF5, mediated $\mathrm{UPR}^{\mathrm{mt}}$ in AECs in response to various mitochondrial stressors. We found that $\mathrm{UPR}^{\mathrm{ER}}$ led to $\mathrm{UPR}^{\mathrm{mt}}$ and mitochondrial dysfunction in an ATF4-dependent manner, but not vice vers $a$, in these cells. We found that alveolar epithelial ATF4 and UPR ${ }^{\mathrm{mt}}$ were induced in the lungs of bleomycin-treated aged mice and patients with IPF. Finally, we found that the inducible expression of ATF4 in mouse AECs aggravated pulmonary UPR ${ }^{\mathrm{mt}}$, lung inflammation, body weight loss, and death in response to bleomycin-induced lung injury.

\section{Methods}

\section{Reagents}

Oligomycin, antimycin A, JC-1 dye, and corn oil were from Sigma-Aldrich.

Doxycycline and tamoxifen were from Cayman Chemical. Tunicamycin was from Cell Signaling Technology. MitoSOX Red reagent was from Thermo Fisher Scientific. The HiPerFect Transfection reagent and RNA isolation kit RNeasy Mini were from Qiagen. Type I collagenase, Dispase II, and DNase I were from Worthington. Bleomycin was from Hospira.

\section{Mice}

12-month-old male C57BL/6 mice were purchased from The Jackson Laboratory. Mice were aged in house to 18 months old for experiments. Mice that inducibly expressed ATF4 in alveolar epithelial type II cells were established by crossbreeding Rosa26-ATF4 ${ }^{\text {loxtg }}$ (stock No. 029394; The Jackson Laboratory) with Sftpc-CreER ${ }^{\mathrm{T} 2}$ (stock No. 028054; The Jackson Laboratory). ATF4 wild-type littermates were used as control mice.

\section{Experimental Pulmonary Fibrosis Model}

The mouse lung fibrosis model was established by intratracheal instillation of bleomycin, as previously detailed (26). All animal experiment protocols were approved by the University of Alabama at Birmingham institutional animal care and use committee.

\section{Cell Lines}

The mouse AEC line MLE-12 was purchased from American Type Culture Collection.

\section{Human Lung Tissues}

IPF and failed donor lung tissues were obtained from the University of Alabama Birmingham Tissue Procurement and Cell Culture Core. The protocol was approved by the University of Alabama at Birmingham institutional review board.

\section{Isolation of Primary Mouse AECs}

Mouse primary AECs were isolated as previously described (27). Detailed methods are described in the data supplement.

\section{Hydroxyproline Measurements \\ This assay is described in the data supplement.}

\section{Fluorescent Immunohistochemistry}

Detailed methods are described in the data supplement.

\section{Real-Time PCR}

mRNA levels were determined by real-time PCR using SsoAdvanced Universal SYBR Green Supermix (Bio-Rad). Primer sequences are listed in Table E1 in the data supplement. To calculate fold change in the expression of these genes, $\Delta \mathrm{Ct}=\mathrm{Ct}$ of tubulin minus $\mathrm{Ct}$ of individual genes was first obtained. $\Delta \Delta \mathrm{Ct}=\Delta \mathrm{Ct}$ of treated groups minus $\Delta \mathrm{Ct}$ of untreated control groups was then obtained. Fold change was calculated as $2^{\Delta \Delta \mathrm{Ct}}$, with control groups as one fold.

\section{Western Blotting}

Western blotting was performed as previously described (28). Mouse anti- $\alpha$ tubulin (T5168) and anti- $\beta$-actin (A2228) antibodies were from Sigma-Aldrich.

Rabbit anti-ATF4 (118155), rabbit anti-BIP (3177), rabbit anti-eIF2 $\alpha$ (5324), and rabbit anti-p-eIF2 $\alpha$ (3398) antibodies were from Cell Signaling Technology. Rabbit antiLONP1 (15440-1-AP), rabbit anti-HSPA9 (14887-1-AP), and rabbit anti-HSPD1 (15282-1-AP) antibodies were from Proteintech.

\section{ELISA}

This assay is described in the data supplement. 
A
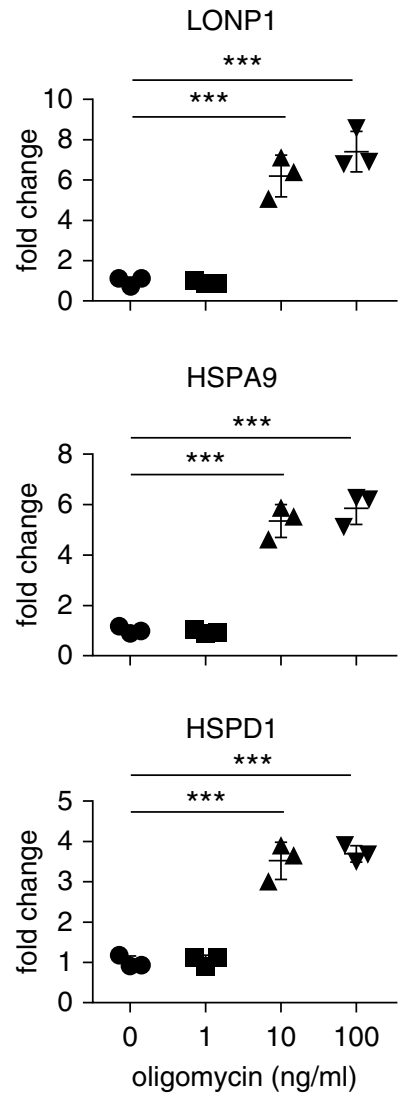

C

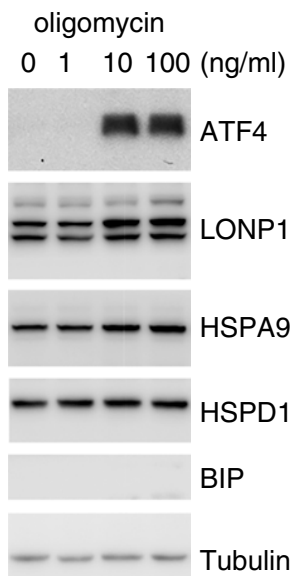

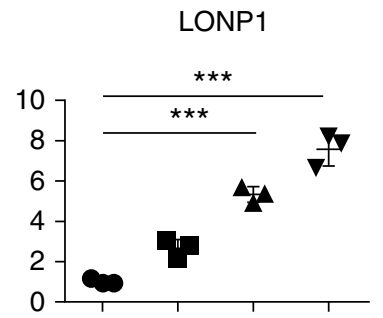
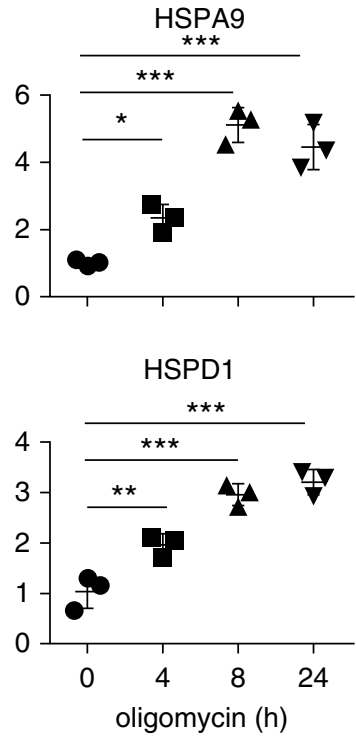

$$
\begin{aligned}
& \text { oligomycin } \\
& \begin{array}{lllll}
0 & 4 & 8 & 24 & \text { (h) }
\end{array}
\end{aligned}
$$

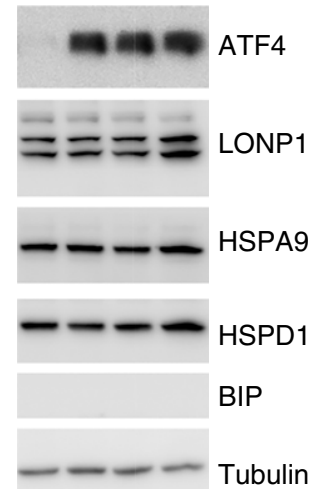

B
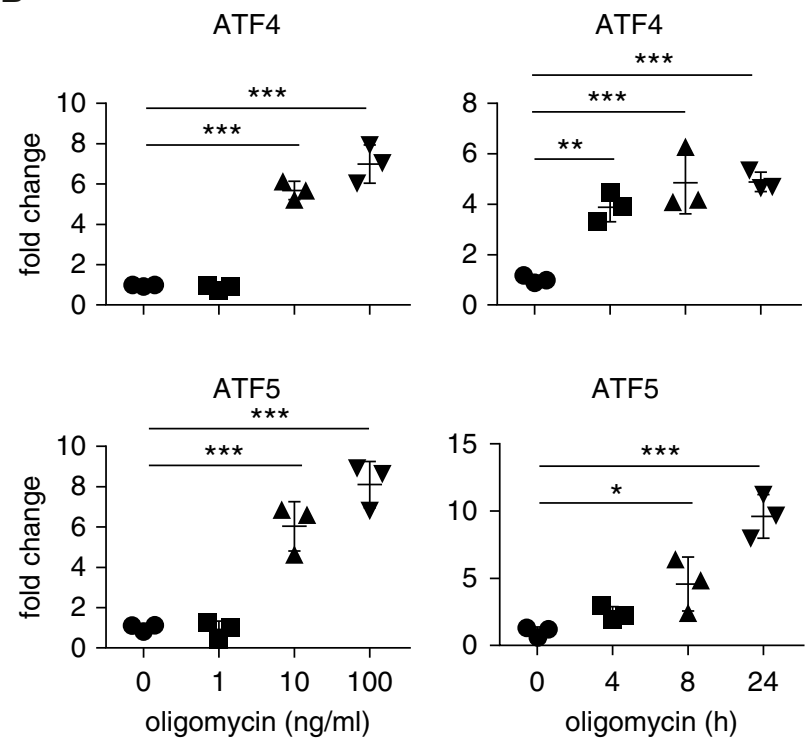

ATF5

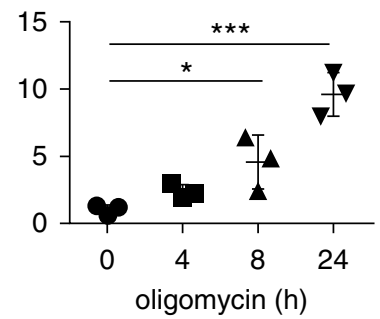

D

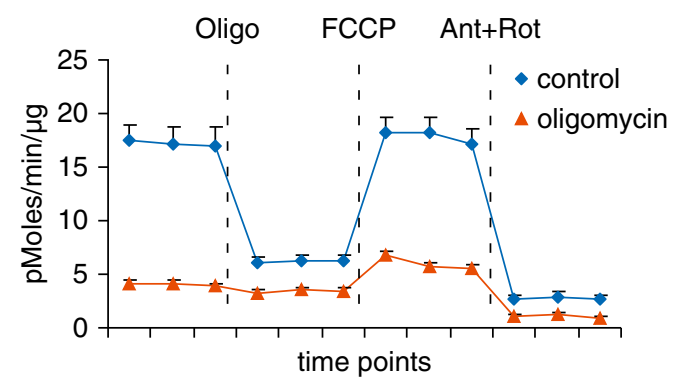

$\mathbf{E}$

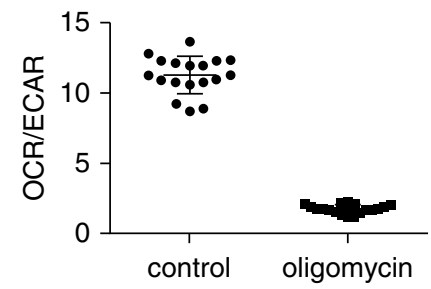

Figure 1. Mitochondria stress induces mitochondrial unfolded protein response in alveolar epithelial cells. (A-C) Alveolar epithelial cell line MLE-12 was treated with oligomycin at increasing concentrations for 24 hours or at $10 \mathrm{ng} / \mathrm{ml}$ for increasing durations of time. RNAs or protein extracts were prepared, and concentrations of indicated gene transcripts or proteins were determined by real-time PCR or Western blotting. $(A$ and $B) n=3$; mean \pm SD. ${ }^{\star} P<0.05,{ }^{* *} P<0.01$, and ${ }^{* * *} P<0.001$. One-way ANOVA followed by Bonferroni test; representative of two independent experiments. ( $D$ and $E$ ) MLE-12 was plated on Seahorse XF-24 microplates and treated with or without $10 \mathrm{ng} / \mathrm{ml}$ oligomycin overnight. (D) Real-time OCR was recorded and normalized by protein concentration. $(E)$ The ratio of the basal OCR to ECAR was calculated. $n=5$ for each condition; mean \pm SE. Representative of three independent experiments. Ant = antimycin; ATF4 = activating transcription factor 4; BIP= binding immunoglobulin protein; ECAR=extracellular acidification rate; FCCP = carbonyl cyanide-4-(trifluoromethoxy)phenylhydrazone; HSPA9= heat shock protein family A (Hsp70) member 9; HSPD1 = heat shock protein family D (Hsp60) member 1; LONP1 = mitochondrial Lon protease 1; OCR = oxygen consumption rate; oligo = oligomycin; Rot = rotenone 


\section{Determination of Mitochondrial \\ Reactive Oxygen Species}

This assay is described in the data supplement.

\section{Mitochondrial Membrane Potential \\ Assay}

This assay is described in the data supplement.

\section{siRNA and Plasmid Transfection}

Details are provided in the data supplement.

\section{Real-Time Cell Metabolism Assay}

XF-24 and XF-96 Bio-Analyzers (Seahorse Bioscience) were used to record the oxygen consumption rate (OCR) and extracellular acidification rate (ECAR), as described previously (29). The assay is described in the data supplement.

\section{Statistics}

One-way ANOVA followed by the Bonferroni test was used for multiple group comparisons. The two-tailed Student's $t$ test was used for comparison between two groups. $P<0.05$ was considered statistically significant.

\section{Results}

\section{Mitochondria Stress Induces UPR ${ }^{\mathrm{mt}}$ in AECs}

We found that the inhibition of mitochondrial ATP synthase by oligomycin dose- and time-dependently induced $\mathrm{UPR}^{\mathrm{mt}}$ in AECs, as evidenced by the increased expressions of the mitochondrial chaperon proteins HSPA9 (heat shock protein family
A [Hsp70] member 9) and HSPD1 (heat shock protein family D [Hsp60] member 1) and of LONP1 (mitochondrial Lon protease 1) (Figures $1 \mathrm{~A}$ and 1C). Oligomycin-caused mitochondrial stress in the treated cells was confirmed by the impaired mitochondrial respiration, which led to an increased dependence on glycolysis (Figures 1D and 1E). Similarly, the doxycycline inhibition of mitochondrial ribosome activity and antimycin $\mathrm{A}$ inhibition of the mitochondrial oxidative phosphorylation also induced $\mathrm{UPR}^{\mathrm{mt}}$ (Figure E1A). In contrast, mitochondrial stress apparently did not activate $\mathrm{UPR}^{\mathrm{ER}}$, as indicated by little induction of the ER chaperon protein BIP (binding immunoglobulin protein) in the treated cells (Figure 1C). In addition to
A

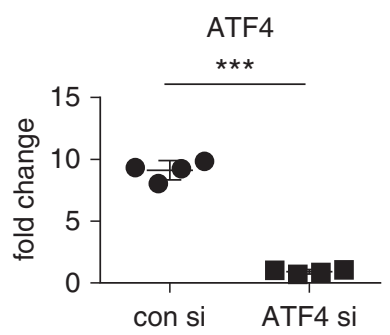

B

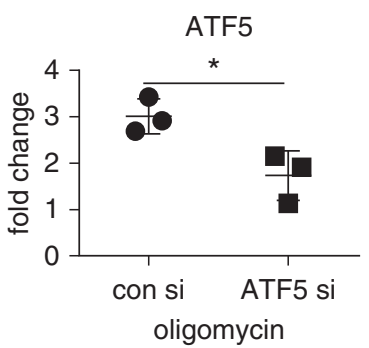

C

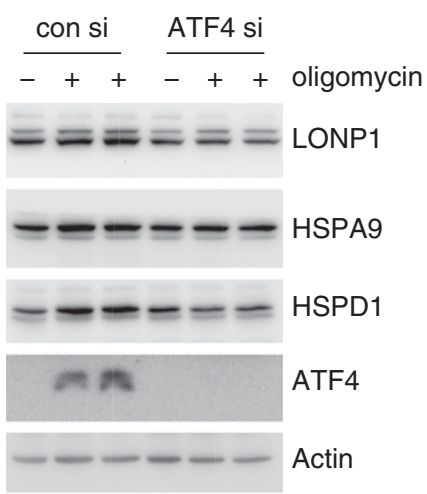

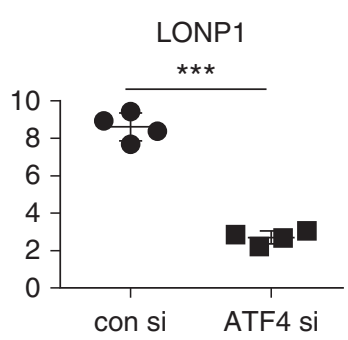
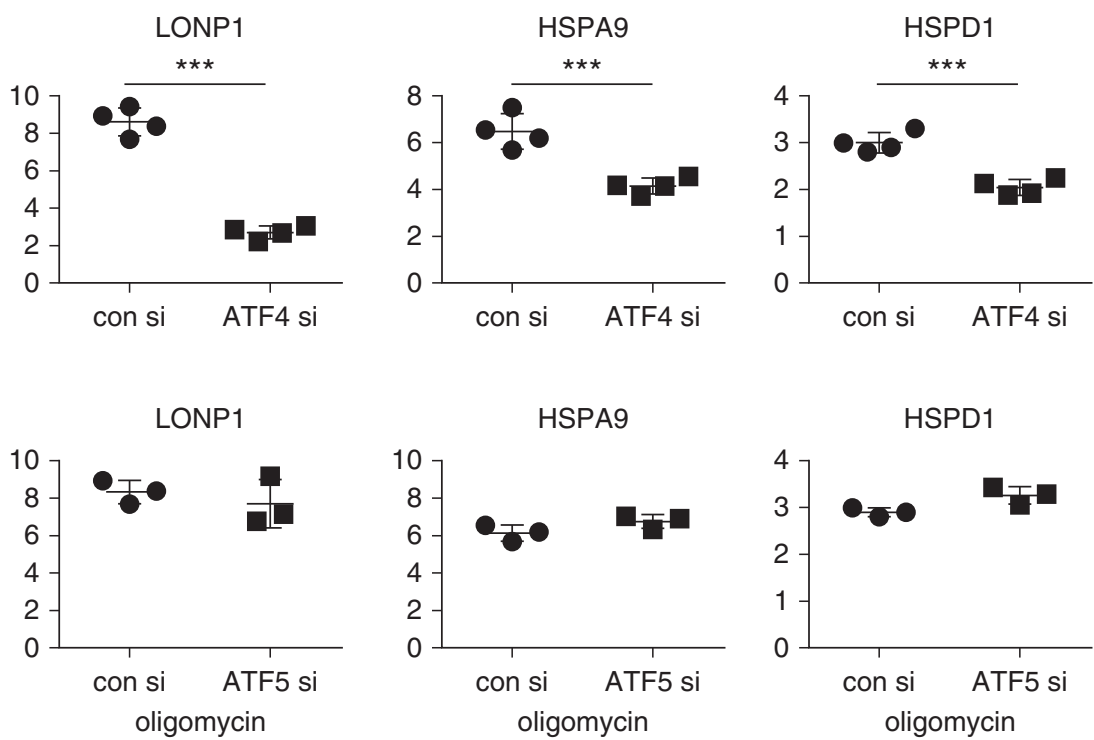

D

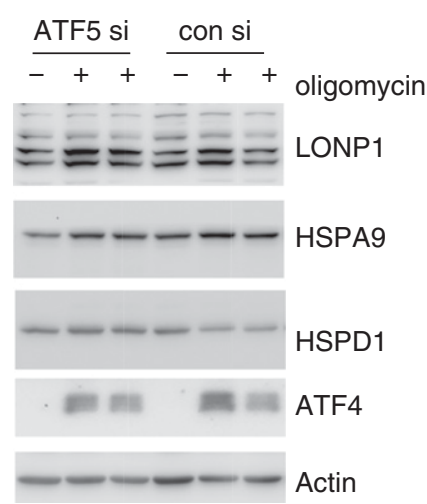

Figure 2. ATF4, but not ATF5, mediates the mitochondrial unfolded protein response in alveolar epithelial cells. (A-D) MLE-12 cells were transfected with control, ATF4, or ATF5 siRNAs. Two days after transfection, the cells were treated with or without $10 \mathrm{ng} / \mathrm{ml}$ oligo1ycin for 24 hours. Concentrations of indicated gene transcripts or proteins were determined by real-time PCR or Western blotting. $(A$ and $B) n=3-4 ;$ mean $\pm S D$. ${ }^{\star} P<0.05$ and ${ }^{\star \star \star} P<0.001$. One-way ANOVA followed by Bonferroni test; representative of two independent experiments. con = control; si =siRNA. 
A
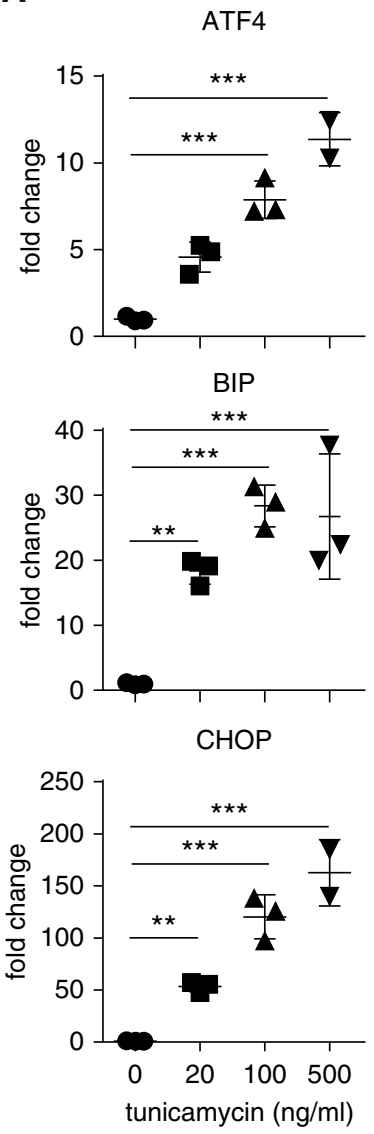

B

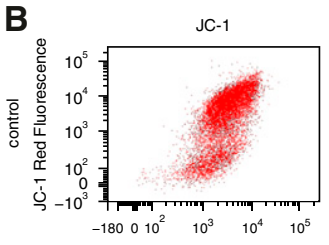

JC-1 Green Fluorescence

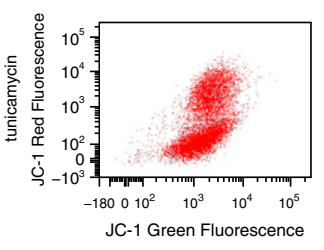

D

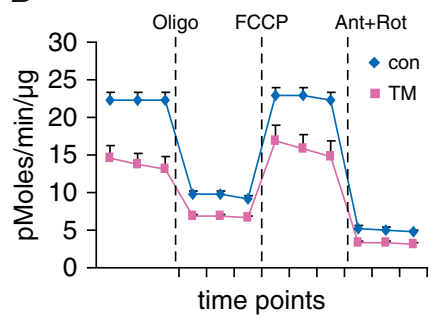

C

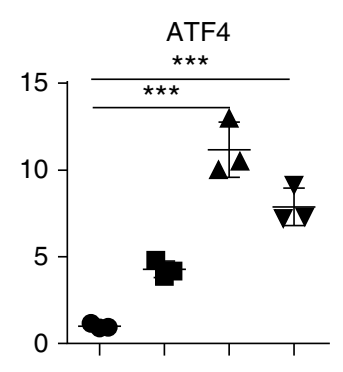

$\mathbf{F}$
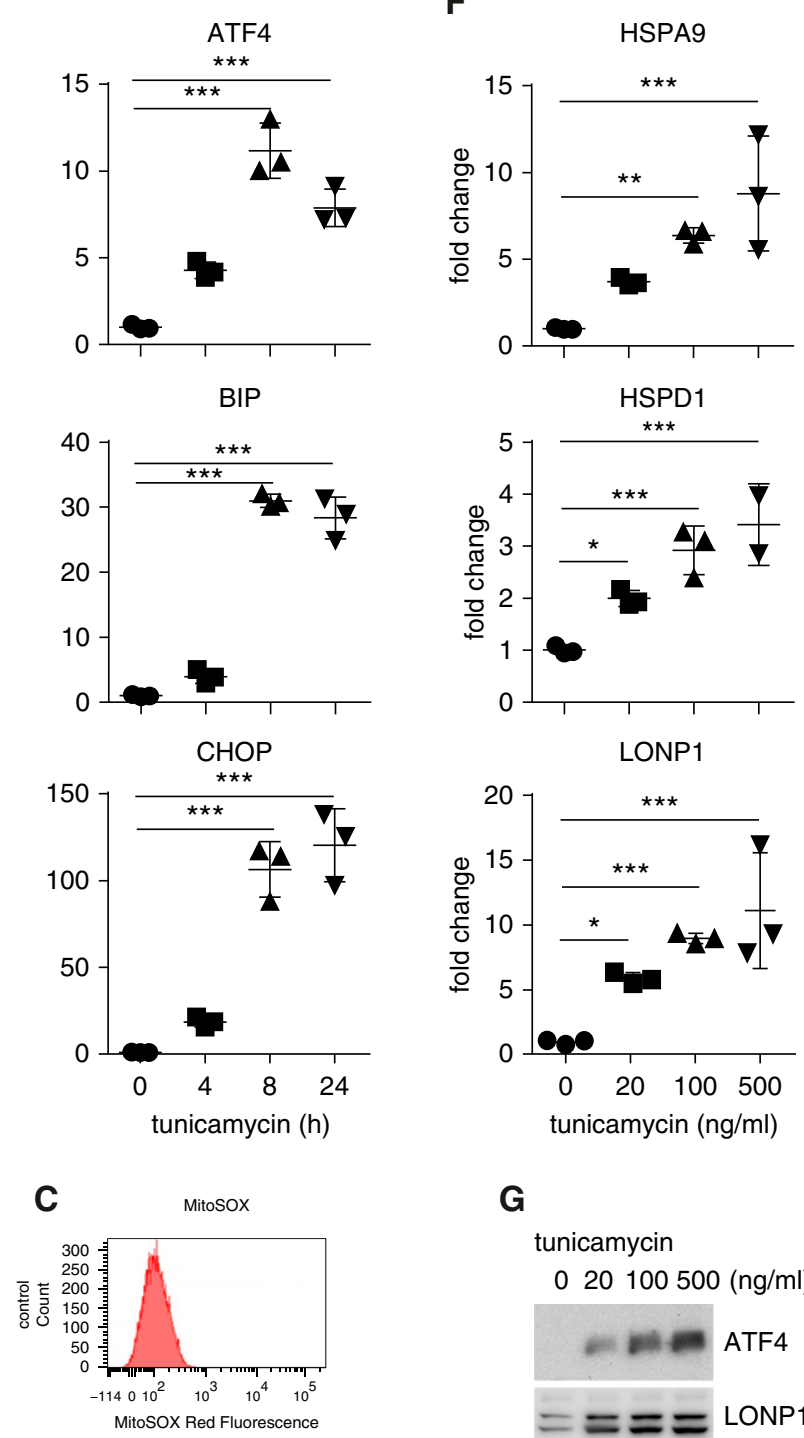

G tunicamycin 020100500 (ng/ml)

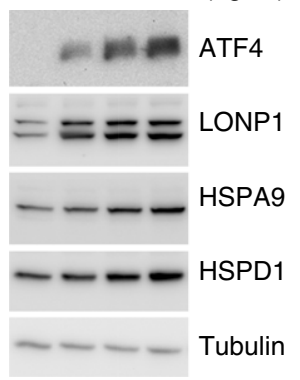

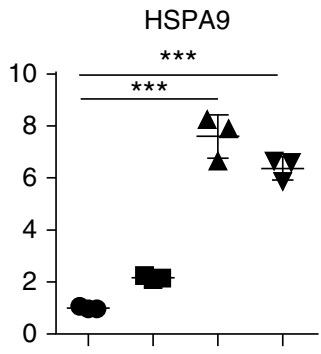
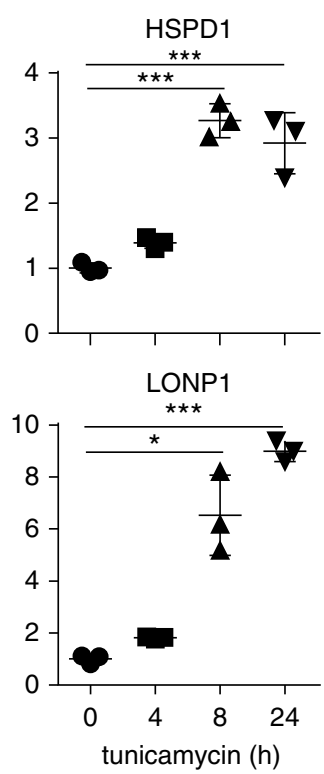

tunicamycin $\begin{array}{lllll}0 & 4 & 8 & 24 & (\mathrm{~h})\end{array}$

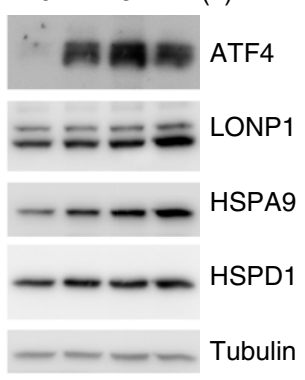

E

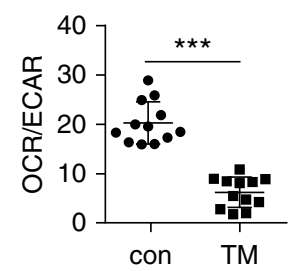

Figure 3. Endoplasmic reticulum unfolded protein response leads to mitochondrial dysfunction and activates mitochondrial unfolded protein response in alveolar epithelial cells. (A) MLE-12 was treated with tunicamycin at increasing concentrations for 24 hours or at $100 \mathrm{ng} / \mathrm{ml}$ for increasing durations of time. RNAs were prepared, and concentrations of indicated gene transcripts were determined by real-time PCR. $n=3 ; m e a n \pm S D$. ${ }^{*} P<0.01$ and ${ }^{\star \star \star} P<0.001$. One-way ANOVA followed by Bonferroni test; representative of two independent experiments. (B and $\left.C\right)$ MLE-12 was treated with 100 ng/ml 
the UPR ${ }^{\mathrm{mt}}$ markers, these mitochondrial stressors also markedly upregulated ATF4 and ATF5 at both transcriptional and protein levels (Figures $1 \mathrm{~B}$ and $1 \mathrm{C}$ and $\mathrm{E} 1 \mathrm{~B}$ ). Taken together, our findings suggest that mitochondrial stress impairs mitochondrial proteostasis in AECs and thereby induces $\mathrm{UPR}^{\mathrm{mt}}$.

\section{ATF4, but Not ATF5, Mediates UPR ${ }^{\mathrm{mt}}$ in AECs}

$\mathrm{UPR}^{\mathrm{mt}}$ has been best characterized in C. elegans, which is regulated by the transcriptional factor ATFS-1 (8). Recent studies indicate that there are several potentially orthologous transcription factors to ATFS-1 in mammals, including ATF4, ATF5, and CHOP $(5,10,11)$. However, it is unclear what the primary regulator of $\mathrm{UPR}^{\mathrm{mt}}$ is in AECs.

Because we had found that both ATF4 and ATF5 were upregulated together with $\mathrm{UPR}^{\mathrm{mt}}$ in the AECs treated with mitochondrial stressors, we then determined whether these two transcriptional factors participate in $\mathrm{UPR}^{\mathrm{mt}}$ in these cells. As shown in Figures 2A and 2C, knocking down ATF4 diminished the induction of LONP1, HSPA9, and HSPD1, suggesting that ATF4 is required for $\mathrm{UPR}^{\mathrm{mt}}$ in AECs. In contrast, ATF5 knockdown had no effect on the oligomycin-induced expression of the $\mathrm{UPR}^{\mathrm{mt}}$ markers (Figures $2 \mathrm{~B}$ and 2D). Together, these data suggest that ATF4, but not ATF5, mediates UPR ${ }^{\mathrm{mt}}$ in AECs.

\section{UPR $^{\mathrm{ER}}$ Leads to Mitochondrial Dysfunction and Activates UPR ${ }^{\mathrm{mt}}$ in} AECs

Unlike $U P R^{\mathrm{mt}}$, the $U P R^{\mathrm{ER}}$ regulation is well delineated in mammalian cells. The primary function of $U P R^{\mathrm{ER}}$ is to restore proteostasis in the ER, but it can also drive signaling toward apoptosis if the damage is insurmountable $(1,2)$. $\operatorname{UPR}^{\mathrm{ER}}$ is frequently found in the AECs from a number of pulmonary diseases, and it has been mechanistically implicated in those disorders (18-25). However, how $\mathrm{UPR}^{\mathrm{ER}}$ is involved in the pathogenesis remains poorly understood. Given plentiful previous evidence that the preferential induction of ATF4 is a key step and a putative responding arm of $\mathrm{UPR}^{\mathrm{ER}}$ as well as our finding that ATF4 is required for $\mathrm{UPR}^{\mathrm{mt}}$ in the AECs, we were intrigued to ask whether $\mathrm{UPR}^{\mathrm{mt}}$ is a consequential event of $\mathrm{UPR}^{\mathrm{ER}}$ in these cells.

To address this question, we treated AECs with a widely used $U P R^{E R}$ inducer, tunicamycin. As expected, tunicamycin triggered $U P R^{\mathrm{ER}}$, as evidenced by the upregulation of ATF4, BIP, and CHOP in these cells (Figure 3A). However, this treatment also caused mitochondrial dysfunction, including decreased mitochondrial membrane potential, increased mitochondrial reactive oxygen species (ROS) production, and impaired mitochondrial respiration (Figures 3B-3E). Furthermore, we found that tunicamycin induced $\mathrm{UPR}^{\mathrm{mt}}$, as evidenced by increased expressions of the $\mathrm{UPR}^{\mathrm{mt}}$ markers LONP1, HSPA9 and HSPD1, similar to those mitochondrial stressors (Figures $3 \mathrm{~F}$ and $3 \mathrm{G}$ ). Taken together, these findings suggest that ATF4 is a pivotal player in $\mathrm{UPR}^{\mathrm{ER}}$-induced $\mathrm{UPR}^{\mathrm{mt}}$ and mitochondrial dysfunction in AECs.

\section{$U R^{E R}$-activated UPR ${ }^{m t}$ Requires ATF4 in AECs}

To test the hypothesis, we determined the role of ATF4 in $\mathrm{UPR}^{\mathrm{ER}}$-induced $\mathrm{UPR}^{\mathrm{mt}}$ in AECs. As shown in Figures $4 \mathrm{~A}$ and $4 \mathrm{~B}$, the knockdown of ATF4 diminished the tunicamycin-induced expression of LONP1, HSPA9 and HSPD1. In addition, although ATF4 overexpression alone did not upregulate the $\mathrm{UPR}^{\mathrm{mt}}$ markers, it did amplify their inductions in tunicamycintreated cells (Figures 4C and 4D). Taken together, these findings suggest that ATF4 alone is not sufficient, but is nevertheless required, for $U P R^{\mathrm{ER}}$-activated $\mathrm{UPR}^{\mathrm{mt}}$ in AECs. Similar to those found with mitochondrial stressors (Figures 2B and 2D), ATF5 appeared unnecessary for $\mathrm{UPR}^{\mathrm{ER}}$ induced $\mathrm{UPR}^{\mathrm{mt}}$ in these cells (Figure 4F).

\section{Downregulation of ATF4 Mitigates $\mathrm{UPR}^{\mathrm{ER}}$-induced Mitochondrial Dysfunction in AECs}

Given that ATF4 is required for $U P R^{E R}$ activated $U P R^{\mathrm{mt}}$, we next determined how ATF4 regulates mitochondrial function in
AECs under ER stress. We found that ATF4 knockdown ameliorated the mitochondrial dysfunction induced by tunicamycin, as evidenced by the improved mitochondrial respiration and membrane potential and reduced ROS production compared with the control cells (Figures 5A-5E). In addition, like the effect on $\mathrm{UPR}^{\mathrm{mt}}$, ATF4 overexpression suppressed the mitochondrial respiration in tunicamycin-treated AECs (Figure 5F). Collectively, these data suggest that $\mathrm{UPR}^{\mathrm{ER}}$ impairs mitochondrial function through the induced ATF4.

\section{ATF4 is Upregulated in the AECs of Aged Mice with Bleomycin-induced Lung Fibrosis and Patients with IPF} It has been well documented that $U P R^{E R}$ plays an important role in the pathogenesis of pulmonary fibrosis, in particular that associated with the aged population (18, 30). Having had shown that ATF4 was required for $U P R^{\mathrm{ER}}$-induced $U P R^{\mathrm{mt}}$, we were prompted to evaluate this stress response in the AECs of fibrotic lungs. As shown in Figure 6A, alveolar epithelial ATF4 showed a trend of upregulation in old mice with bleomycin-induced lung fibrosis compared with that in the salinetreated control mice. Consistent with the ATF4 elevation, there was an increased expression of the UPR ${ }^{\mathrm{mt}}$ markers in these cells (Figure 6A). Furthermore, ATF4 and the $\mathrm{UPR}^{\mathrm{mt}}$ markers were also upregulated in the AECs of patients with IPF, which was accompanied by the reduced epithelial cell marker E-cadherin in these cells (Figure 6B). Together, these data suggest that $\mathrm{UPR}^{\mathrm{mt}}$ is a common phenomenon in the AECs in pulmonary fibrosis and may play a role in its pathogenesis.

\section{AEC Overexpression of ATF4 Alone Does Not Cause Lung Fibrosis}

We have shown that ATF4 is upregulated by mitochondrial and ER stresses, and it is required for $U P R^{E R}$-induced mitochondrial dysfunction and $\mathrm{UPR}^{\mathrm{mt}}$ in AECs. We also found that ATF4 is increased in the AECs in the fibrotic lung of aged mice and patients with IPF. We asked whether ATF4 upregulation in AECs

Figure 3. (Continued). tunicamycin for 24 hours. Cells were incubated with JC-1 or MitoSOX dye and analyzed by flow cytometry. ( $D$ and $E$ ) MLE-12 was plated on Seahorse XF-24 microplates and treated with or without tunicamycin. (D) Real-time OCR was recorded and normalized by protein concentration. $(E)$ The ratio of basal OCR to ECAR was calculated. $n=5$ for each condition; mean $\pm \mathrm{SD}$; ${ }^{* \star} P<0.001$. Representative of two independent experiments. ( $F$ and $G$ ) MLE-12 was treated as in $A$. Concentrations of the indicated transcripts and proteins were determined. $n=3$; mean \pm SD. ${ }^{\star} P<0.05,{ }^{* \star} P<0.01$, and ${ }^{* \star *} P<0.001$. Representative of two independent experiments. CHOP $=\mathrm{C} / \mathrm{EBP}$ homologous protein; TM=tunicamycin. 
A
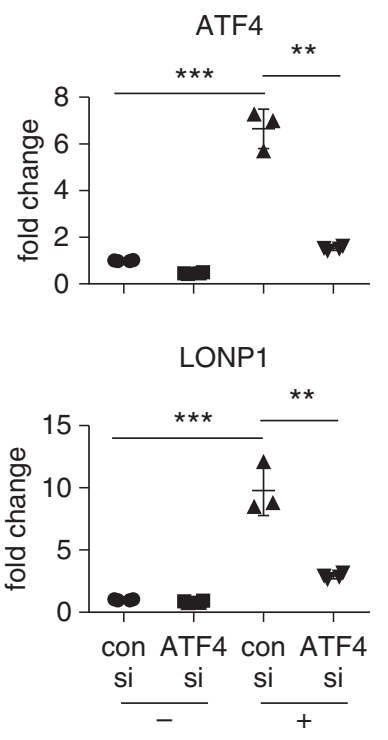

tunicamycin
HSPA9

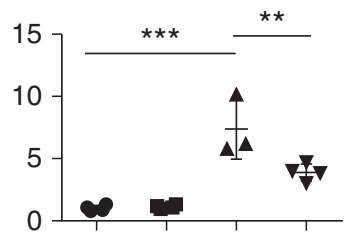

HSPD1

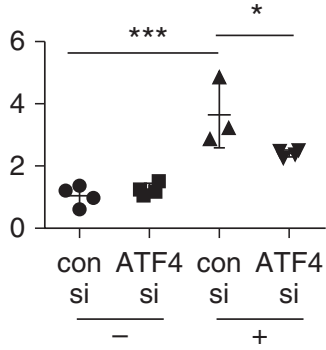

tunicamycin
E

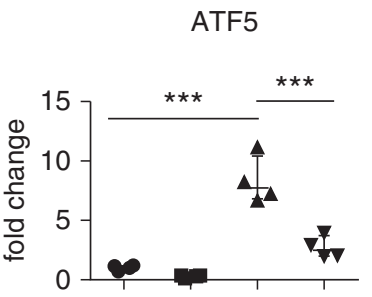

LONP1

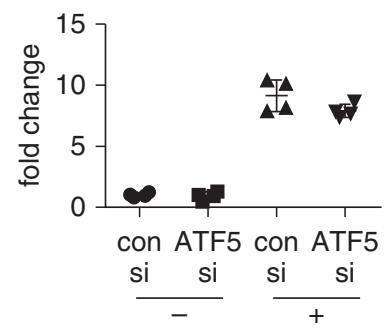

tunicamycin
HSPA9

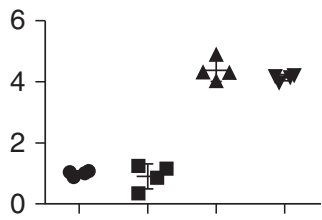

HSPD1

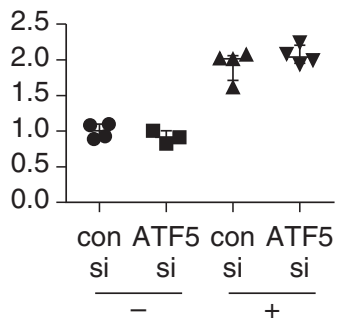

tunicamycin
B

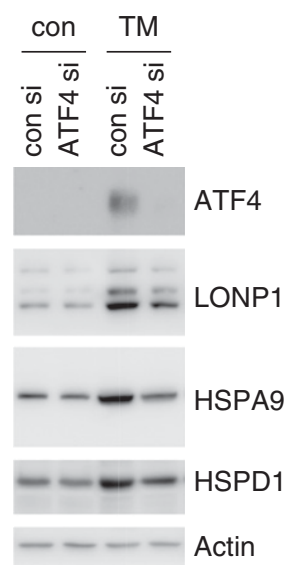

C

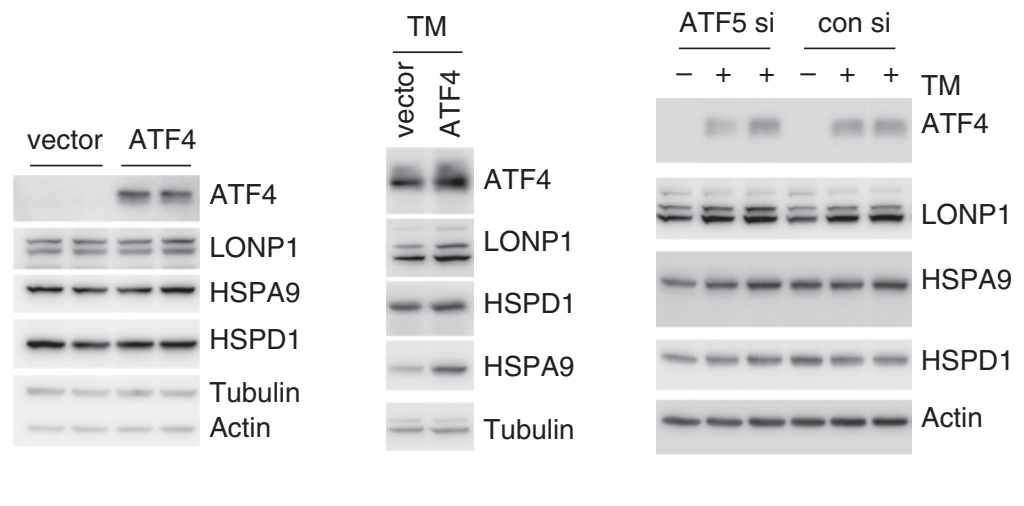

D

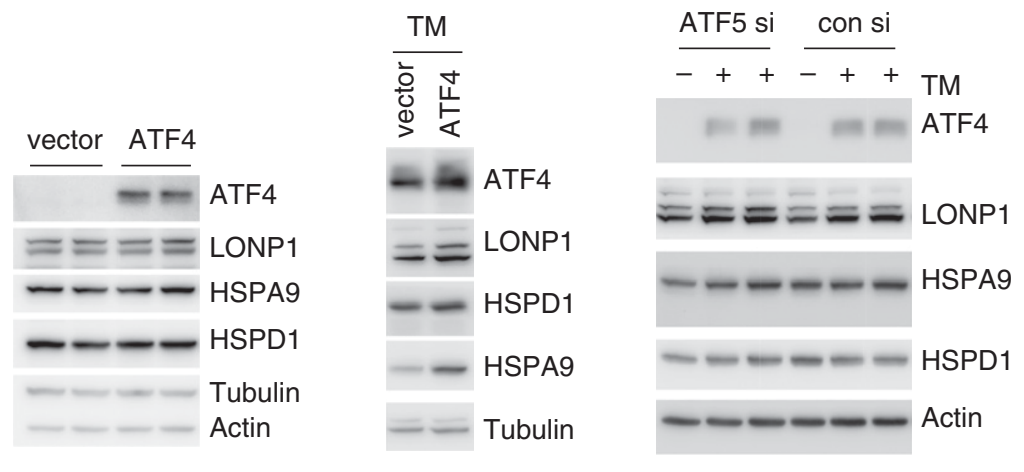

F

Figure 4. Endoplasmic reticulum unfolded protein response-activated mitochondrial unfolded protein response requires ATF4 in alveolar epithelial cells. $(A$ and $B)$ MLE-12 cells were transfected with control or ATF4 siRNAs. Two days after transfection, the cells were treated with or without $100 \mathrm{ng} / \mathrm{ml}$ tunicamycin for 24 hours. Concentrations of indicated gene transcripts or proteins were determined. $n=3-4$; mean \pm SD. ${ }^{\star} P<0.05$, ${ }^{\star \star} P<0.01$, and ${ }^{\star \star \star} P<0.001$. One-way ANOVA followed by Bonferroni test; representative of two independent experiments. $(C$ and $D)$ MLE- 12 cells were transfected with control or ATF4-expressing construct. Two days after transfection, the cells were treated without $(C)$ or with $(D) 100 \mathrm{ng} / \mathrm{ml}$ tunicamycin for $24 \mathrm{hours}$. Concentrations of indicated proteins were determined. $n=3-4$; representative of two independent experiments. (E and $F)$ MLE-12 cells were transfected with control or ATF5 siRNAs. Two days after transfection, the cells were treated with or without $100 \mathrm{ng} / \mathrm{ml}$ tunicamycin for 24 hours. Concentrations of indicated gene transcripts or proteins were determined. $n=4$; mean $\pm \mathrm{SD}$. ${ }^{\star \star \star} P<0.001$. Representative of two independent experiments.

leads to lung fibrosis. To test this hypothesis, a transgenic mouse line that can inducibly overexpress ATF4 in alveolar type II cells was established (Figures 7A and 7B). Unexpectedly, we found that there was no fibrosis in the lung at 3 weeks after ATF4 overexpression was induced (Figure E2), indicating that ATF4 alone is insufficient for causing this pathology. We also found that there was no UPR ${ }^{\mathrm{ER}}$ or $\mathrm{UPR}^{\mathrm{mt}}$ in the lungs of the ATF4-overexpressing animals (Figure 7B).

\section{AEC Overexpression of ATF4 Augments Bleomycin-induced Lung Injury in Mice}

Given that ATF4 overexpression alone failed to result in lung fibrosis, we asked whether this is a susceptibility factor for the pathogenesis. To test the hypothesis, transgenic mice with or without ATF4 overexpression in AECs were initially treated with $0.75 \mathrm{U} / \mathrm{kg}$ bleomycin, a dosage that is half of the amount normally used in the lung fibrosis mouse model. However, we were unable to evaluate the severity of this pathology because all the ATF4 
A
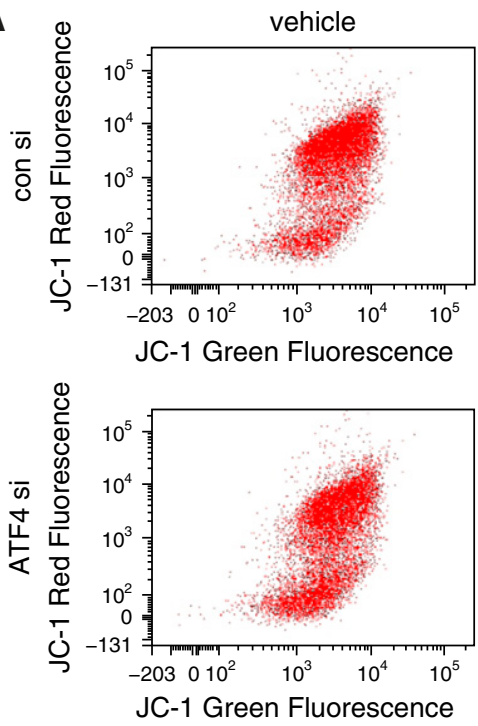

C
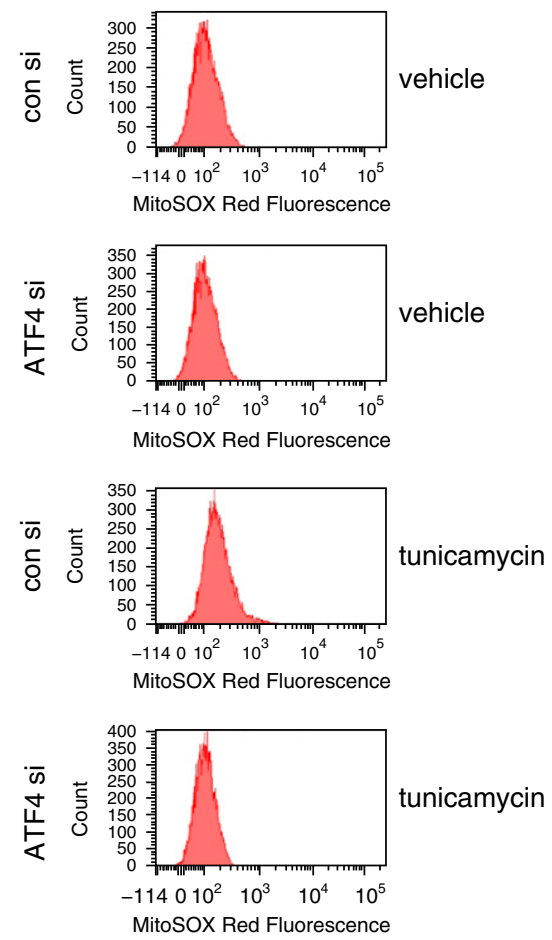
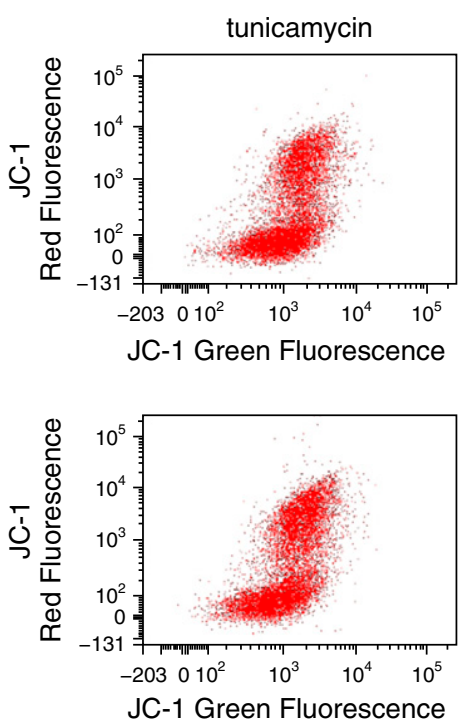

D

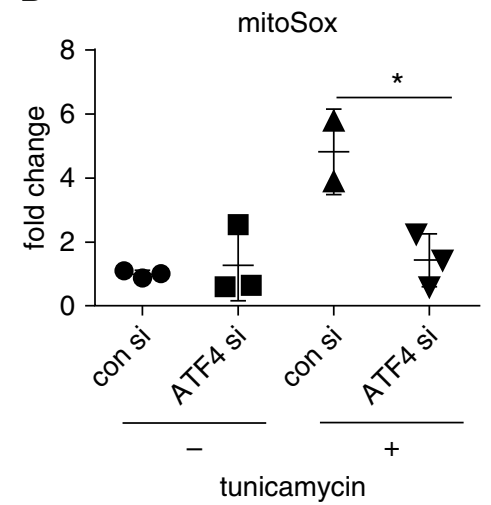

B
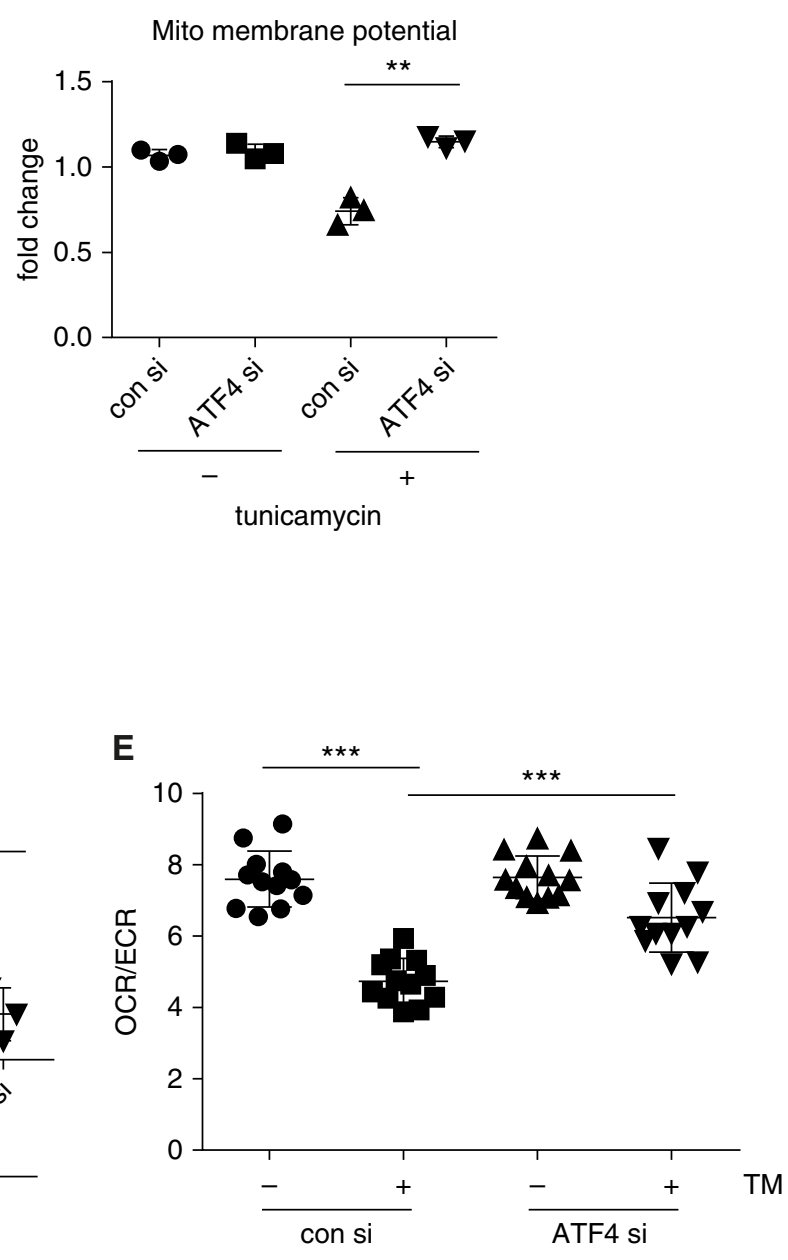

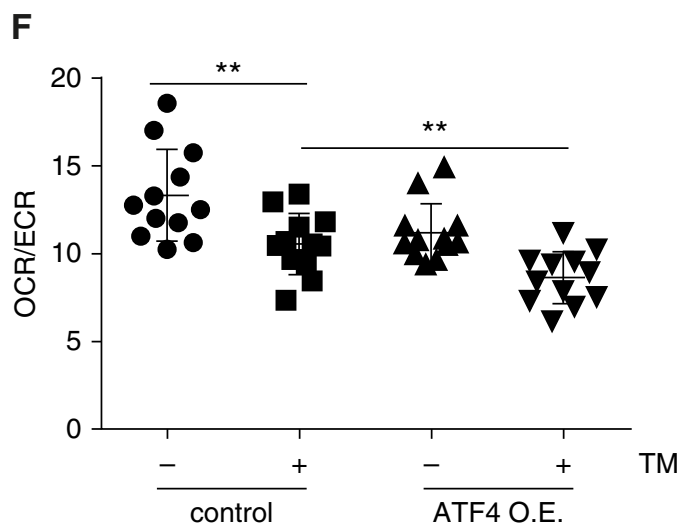

Figure 5. The downregulation of ATF4 mitigates endoplasmic reticulum unfolded protein response-induced mitochondrial dysfunction in alveolar epithelial cells. $(A-D)$ MLE-12 cells were transfected with control or ATF4 siRNAs. Two days after transfection, the cells were treated with or without $100 \mathrm{ng} / \mathrm{ml}$ tunicamycin for 24 hours. Cells were incubated with $(A$ and $B) \mathrm{JC}-1$ or $(C$ and $D)$ MitosoX dye and analyzed by flow cytometry to evaluate mitochondrial membrane potential or mitochondrial reactive oxygen species production. Data were plotted as fold change. $n=3 ;$ mean \pm SD. ${ }^{*}<<0.05$ and ${ }^{* \star} P<0.01$. One-way ANOVA followed by Bonferroni test. ( $E$ and $\left.F\right)$ MLE-12 cells were transfected with control siRNA $(E)$, ATF4 siRNA $(E)$, control vector $(F)$, or ATF4-expressing construct $(F)$. Two days after transfection, the cells were treated with or without tunicamycin. The oxygen consumption rate and extracellular acidification rate were recorded, and the ratio of the basal oxygen consumption rate to extracellular acidification rate was calculated. $n=4-5$ for each condition; mean \pm SD. ${ }^{\star *} P<0.01$ and ${ }^{* \star *} P<0.001$. Mito = mitochondrial; O.E. $=$ overexpressing. 
A

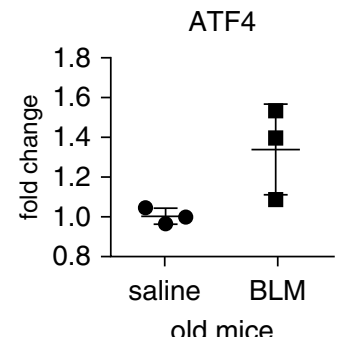

B
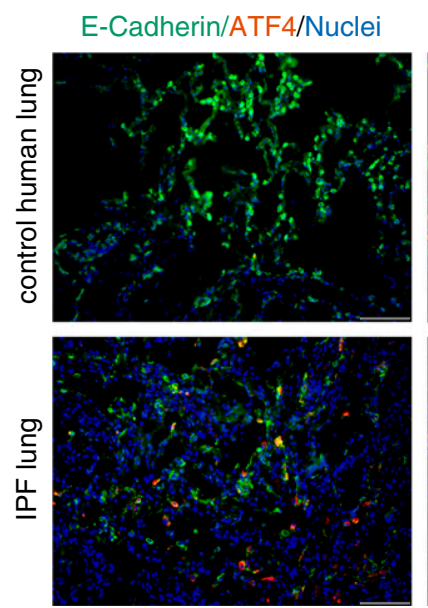

HSPA9

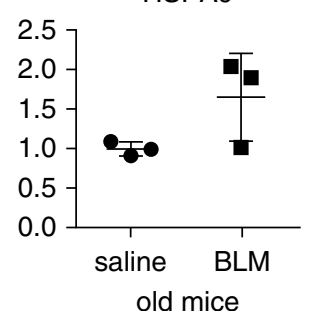

old mice
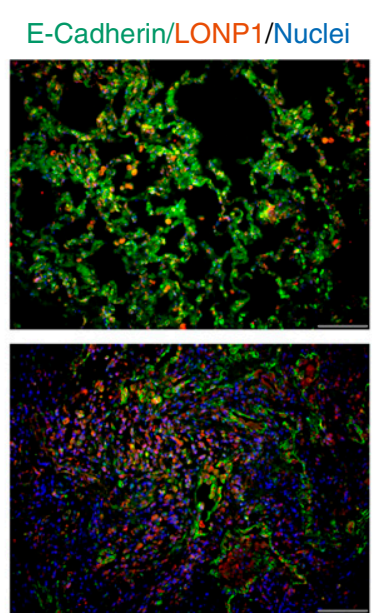

HSPD1

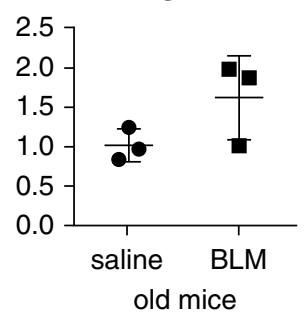

old mice
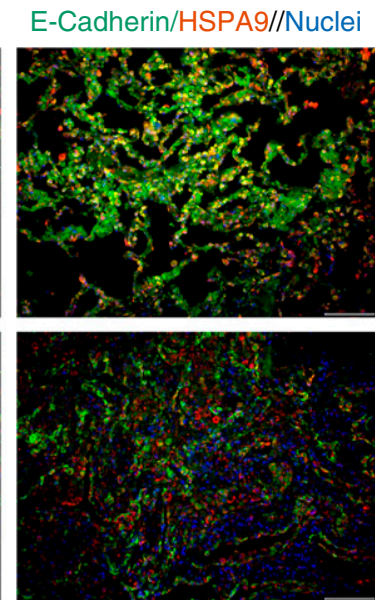

Figure 6. ATF4 is upregulated in the alveolar epithelial cells of aged mice with bleomycin-induced lung fibrosis and patients with idiopathic pulmonary fibrosis. (A) Eighteen-month-old C57BL/6 mice were i.t. instilled with saline or bleomycin. Three weeks later, the mice were killed, and the alveolar epithelial cells were isolated. Concentrations of the indicated RNA transcripts were determined by real-time PCR. $n=3$ for each condition; mean \pm SD. $(B)$ The indicated proteins in the normal human lung and IPF lung were demonstrated by fluorescent immunohistochemistry. Nuclei were stained by DAPI. Scale bars, $100 \mu \mathrm{m}$. BLM = bleomycin; IPF = idiopathic pulmonary fibrosis; i.t. = intratracheally

overexpressing mice succumbed to the bleomycin treatment within 12 days. In contrast, none of the mice without ATF4 overexpression died during the same period (data not shown). We then reduced bleomycin dosage to $0.375 \mathrm{U} / \mathrm{kg}$ and found that the ATF4 overexpression mice were still highly sensitive, as all mice perished less than 2 weeks after the bleomycin treatment (Figure 7C). The ATF4-overexpressing mice also underwent a greater weight loss than the control animals at the end of the first week after treatment (Figure 7C). It is known that bleomycin induces acute lung injury in the first week after intratracheal injection (31). We reasoned that the greater weight loss and mortality in ATF4-

overexpressing mice might be caused by a heightened bleomycin-induced lung injury. To test this, we treated the mice with bleomycin for 3 days and found that mice with ATF4 overexpression demonstrated a worsened lung injury compared with those without ATF4 overexpression, as evidenced by greater BAL protein concentration and proinflammatory cytokine production in these mice (Figures 7D-7F). Furthermore, we found that $\mathrm{UPR}^{\mathrm{mt}}$, but not $\mathrm{UPR}^{\mathrm{ER}}$, markers were considerably increased in mice with ATF4 overexpression compared with those in the control animals (Figures $7 \mathrm{G}$ and $7 \mathrm{H})$. The expression of UPR ${ }^{\mathrm{mt}}$ markers in the lung still demonstrated a trend of elevation even on day 10 after bleomycin injury (Figure 7I). To further determine the mechanistic significance of $\mathrm{UPR}^{\mathrm{mt}}$ in the lung epithelial cells of bleomycin-treated ATF4-overexpressing mice, we examined the expression of pulmonary proapoptotic genes and senescence markers. As shown in Figures $\mathrm{E} 3 \mathrm{~A}$ and $\mathrm{E} 3 \mathrm{~B}$, the concentrations of a group of proapoptotic genes and senescence markers were generally increased in bleomycin-treated ATF4-overexpressing mice compared with those in the control animals. Collectively, these findings with the ATF4-overexpressing mice suggest that ATF4 promotes $\mathrm{UPR}^{\mathrm{mt}}$ in AECs and enhances cellular apoptosis and senescence, thereby aggravating bleomycin-induced acute lung injury.

\section{Discussion}

Recent studies indicate that mammalian ATF5 is the orthologous counterpart of ATFS-1 on the basis of evidence that ATF5 is able to rescue $\mathrm{UPR}^{\mathrm{mt}}$ in ATFS-1 ${ }^{-1-} C$. elegans as well as the finding that ATF5 is required for $U P R^{\mathrm{mt}}$ in the kidney cell line HEK-293 (9). Nevertheless, we found that it is not ATF5 but is rather ATF4 that mediates $\mathrm{UPR}^{\mathrm{mt}}$ in AECs. This notion is supported by the findings that ATF4, but not ATF5, plays an essential role in both ER and mitochondrial stress-induced $\mathrm{UPR}^{\mathrm{mt}}$ in these cells. This discrepancy is currently unclear, but it could be attributed to the concentrations levels of ATF4 and ATF5 in different types of cells. In AECs, although both ATF4 and ATF5 are upregulated by ER and mitochondrial stresses, the amount of ATF5 transcripts is much smaller than that of ATF4. In addition, it should be also acknowledged that these in vitro findings were established in the AEC cell line MLE12 but not in primary lung epithelial cells, mostly because of the technical challenges of manipulating the primary cells by transfection. Future studies with primary lung epithelial cells from ATF4 transgenic mice will be certainly instrumental for a better clarification.

We have shown that $\mathrm{UPR}^{\mathrm{ER}}$ leads to $\mathrm{UPR}^{\mathrm{mt}}$ in AECs. However, it is apparently not the case vice versa because although mitochondrial stressors considerably upregulate $\mathrm{UPR}^{\mathrm{mt}}$ markers, they have a minimal effect on the expression of the ER chaperon BIP in these cells. Although there are reports showing that mitochondrial activities dictate the fate of ER-stressed cells by a mechanism somehow involving oxidative phosphorylation $(17,32)$, there are more studies demonstrating that $\mathrm{UPR}^{\mathrm{ER}}$ has a substantial impact on the mitochondria, including their morphology and mitophagy (33-35). In this study, we establish ATF4 as a linchpin between ER stress and mitochondrial dysfunction in that $\mathrm{UPR}^{\mathrm{ER}}$ induced ATF4 promotes UPR ${ }^{\mathrm{mt}}$ and mitochondrial morbidity. 
A

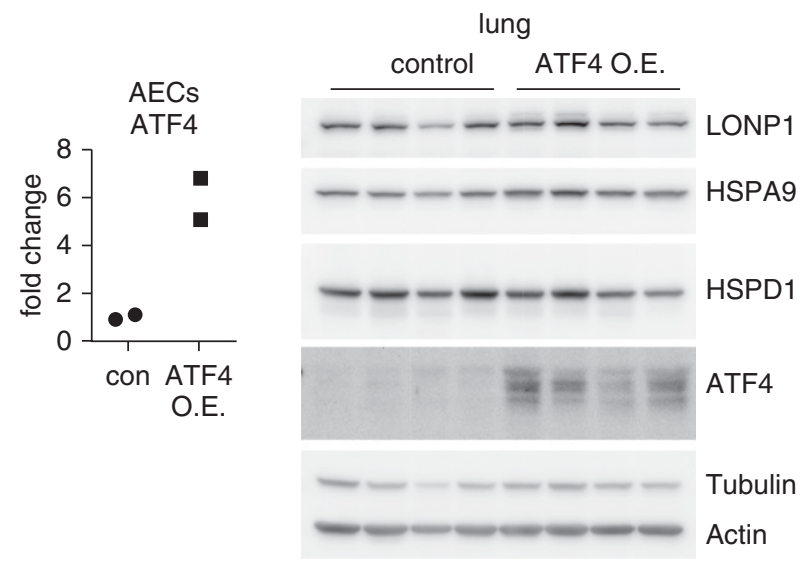

D

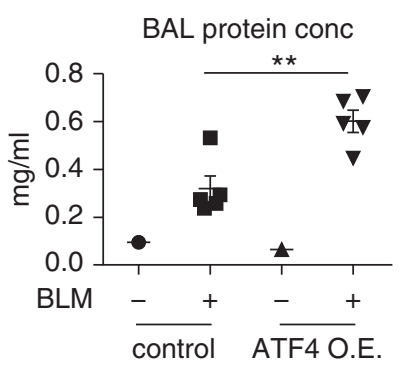

C
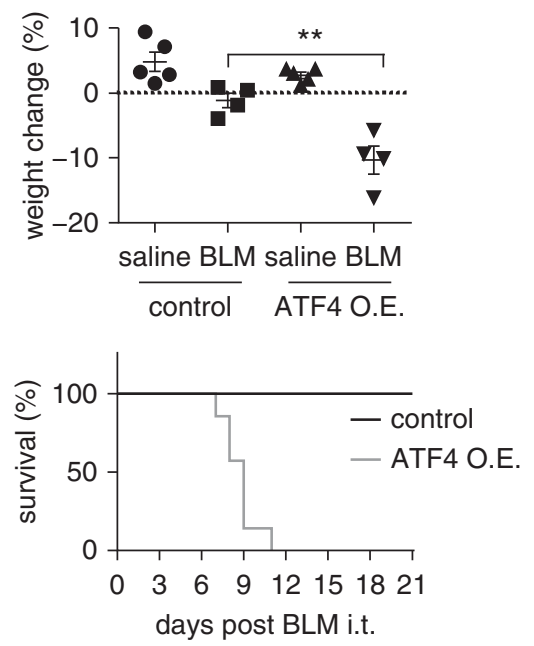

$\mathbf{F}$

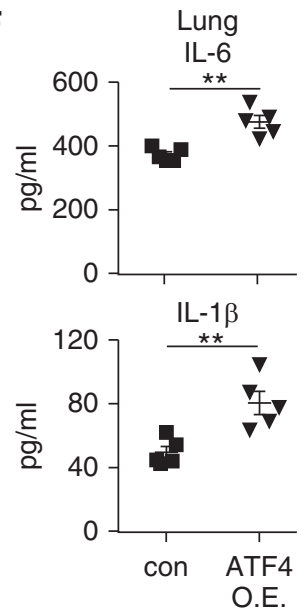

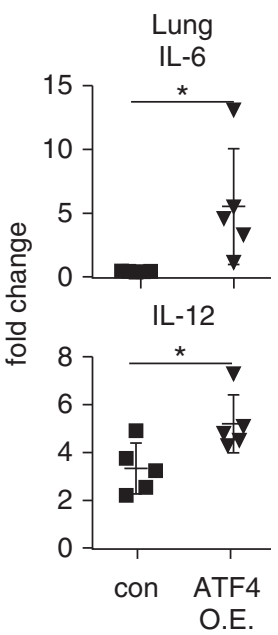

3 days post BLM

3 days post BLM

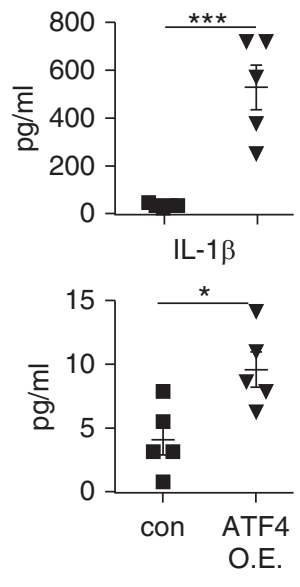

Figure 7. Alveolar epithelial cell overexpression of ATF4 does not lead to pulmonary fibrosis but augments bleomycin-induced lung injury in mice. (A) Three-month old Rosa26-ATF4/Sftpc-CreER mice were i.p. injected with corn oil or tamoxifen (75 mg/kg body weight dissolved in corn oil) once a day for 5 consecutive days. Three days after injection, the mice were killed, and alveolar epithelial cells were isolated. Concentrations of the ATF4 mRNA transcripts were determined by real-time PCR. $n=2$. (B) Rosa26-ATF4/Sftpc-CreER mice were i.p. injected with corn oil or tamoxifen once a day for 5 consecutive days. Three weeks after injection, the mice were killed, and whole lung extracts were prepared. Concentrations of the indicated proteins were determined. (C) Rosa26-ATF4/Sftpc-CreER mice were i.p. injected with corn oil or tamoxifen once a day for 5 consecutive days. Three days after the last injection, the mice were i.t. instilled with saline or bleomycin. Body weights were taken on days 0 and 7 after bleomycin treatment. Weight changes were calculated and plotted (top). The mice were monitored for 3 weeks, and mortality ratios were plotted (bottom). $n=4-7$; mean \pm SEM. ${ }^{\star \star} P<0.01$. ( $D-F$ ) Rosa26-ATF4/Sftpc-CreER mice were i.p. injected with corn oil or tamoxifen once a day for 5 consecutive days. Three days after the last injection, mice were i.t. instilled with saline or bleomycin. Three days after saline or bleomycin treatment, mice were killed, and BALs and lungs were collected. (D) BAL protein and $(E)$ cytokine concentrations and $(F)$ lung cytokine protein and mRNA concentrations were determined. $n=5$ for both groups of the bleomycin-treated mice; mean \pm SEM. ${ }^{*} P<0.05$, ${ }^{* *} P<0.01$, and ${ }^{\star \star *} P<0.001$. ( $G$ and $H$ ) Concentrations of the indicated protein and RNA transcripts in the lungs of the above experiment were determined. $n=5$ for both groups of the bleomycin-treated mice; mean \pm SEM. ${ }^{\star \star} P<0.01$ and ${ }^{\star \star \star} P<0.001$. () Rosa26-ATF4/Sftpc-CreER mice were i.p. injected with corn oil or tamoxifen once a day for 5 consecutive days. Three days after the last injection, mice were i.t. instilled with saline or bleomycin. The surviving mice on day 10 after bleomycin treatment were killed, and the lungs were collected. Concentrations of the indicated mRNA transcripts were determined by real-time PCR. $n=3-4$; mean \pm SEM ${ }^{*} P<0.05$. AECs $=$ alveolar epithelial cells; conc $=$ concentration; i.p. $=$ intraperitoneally.

Although ER stress, especially that encountered by AECs, is widely recognized to play a critical role in the pathogenesis of a number of pulmonary diseases, most of the studies focus on the effect of $\mathrm{UPR}^{\mathrm{ER}}$ on cell viability and transdifferentiation of these cells as potential mechanisms $(25,35-38)$. As often as ER stress occurs, mitochondrial dysfunction has also been frequently found in AECs from many pulmonary disorders $(19,30,39)$. In our study, we showed that ATF4 couples UPR ${ }^{\mathrm{ER}}$ with $\mathrm{UPR}^{\mathrm{mt}}$ in AECs and thereby promotes
ER stress-induced mitochondrial dysfunction in vitro. Furthermore, the inducible expression of ATF4 in AECs greatly sensitizes mice to bleomycin-induced lung injury and mortality. Our data have thus established ATF4 as a potentially important therapeutic target 
G

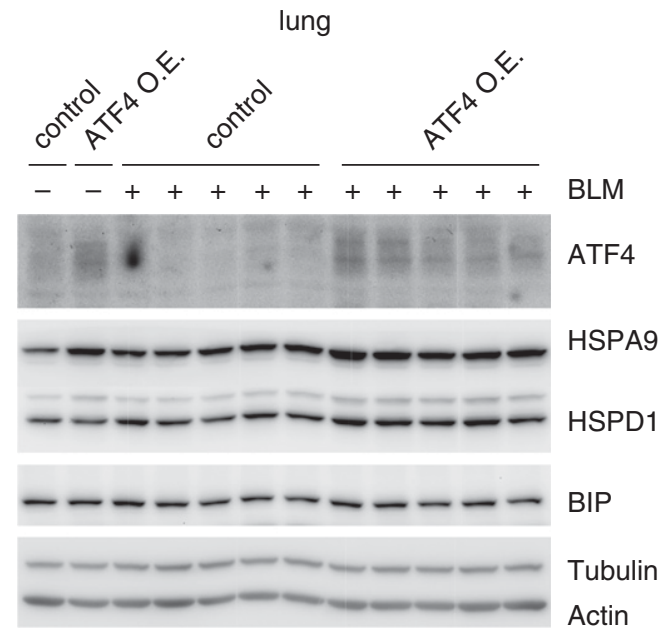

H

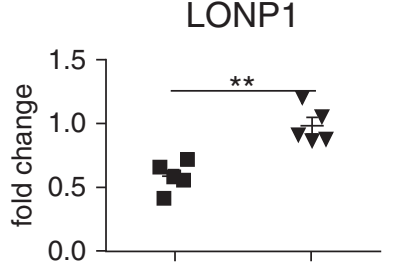

HSPA9
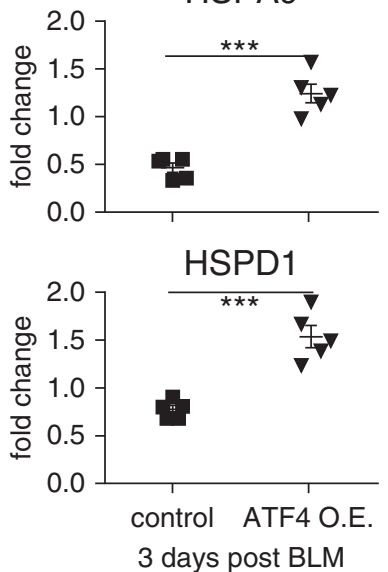

I LONP1

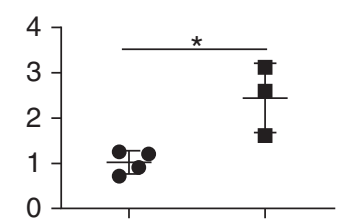

HSPA9
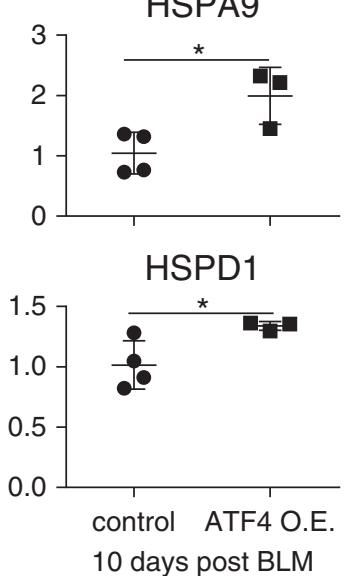

Figure 7. (Continued).

to improve ER and mitochondrial stress-induced UPR ${ }^{\mathrm{mt}}$ in these pulmonary pathologies.

$\mathrm{UPR}^{\mathrm{ER}}$ is also a main component of the integrated stress response, which is elicited by a variety of extrinsic and intrinsic insults, including amino acid deprivation, RNA viral infection, heme deficiency, and ER stress (40-42). The promotion of the ATF4 translation through eIF2 $\alpha$ phosphorylation in response to these stresses is the quintessential regulatory mechanism in this event (40-42). We confirmed that ER stress induces eIF2 $\alpha$ phosphorylation in AECs, but we also found enhanced ATF4 transcription under this condition. Although it is speculated that ATF4 may undergo self-induction after the phosphorylated eIF $2 \alpha$-mediated ATF4 expression in ER-stressed AECs, we do not believe that this is the same scenario for $\mathrm{UPR}^{\mathrm{mt}}$ because the mitochondrial stressors are able to only weakly induce eIF $2 \alpha$ phosphorylation in these cells (Figure E4). Nevertheless, the regulation of ATF4 expression in response to mitochondrial perturbations is worth further investigations because its delineation will certainly improve the understanding of the mechanism underlying ATF4-dependent $\mathrm{UPR}^{\mathrm{mt}}$ in AECs.
This notion is only further reinforced, as we found that, although required, ATF4 alone is insufficient to induce UPR ${ }^{\mathrm{mt}}$ in AECs, as indicated by the general lack of effect of ATF4 overexpression in vitro and in vivo. However, the considerably increased susceptibility to UPR ${ }^{\mathrm{mt}}$ and bleomycin-induced lung injury with ATF4 overexpression suggests that ATF4, although a transcriptional factor, may only function fully in the presence of additional transcriptional regulators, which are concurrently modulated by ER and mitochondrial stresses. Among those, ATF3, another basic-leucine zipper domain transcriptional factor, perhaps represents an example of those potential factors. In fact, ATF3 has been shown to be upregulated in IPF and to promote mitochondrial dysfunctions and cellular senescence in bleomycin-treated lungs (33). In addition, ATF3 and ATF4 were also demonstrated to cooperatively activate the expression of apoptotic genes, such as Noxa, in cancer cells (43). Our finding that bleomycin-treated ATF4-overexpressing mice demonstrated enhanced cellular apoptosis and senescence in the lung lends further support to this hypothesis.

Although $\mathrm{UPR}^{\mathrm{mt}}$ is known to have beneficial effects in certain pathophysiological conditions, such as aging and cardiac ischemia-reperfusion $(44,45)$, it has also been shown to contribute to disease pathogeneses $(16,17)$. $\mathrm{UPR}^{\mathrm{mt}}$ generally leads to slowdown of mitochondrial activity in order for the stressed organelles to return to homeostasis. However, this process also increases the risk of declining mitochondrial oxidative phosphorylation, loss of mitochondrial membrane potential, and enhanced mitochondrial ROS production, as demonstrated in the AECs in this study. These detrimental scenarios may outweigh the overall benefits of UPR ${ }^{\mathrm{mt}}$. Therefore, the role of UPR ${ }^{\mathrm{mt}}$ could be critically dependent on the cell types involved and the context of the pathogeneses.

In summary, we have identified ATF4 as a key regulator of $\mathrm{UPR}^{\mathrm{mt}}$ in AECs. We establish that ATF4 is the linchpin that mediates $\mathrm{UPR}^{\mathrm{ER}}$-induced mitochondrial dysfunction in these cells. Thus, our study provides a novel insight into the molecular mechanism by which UPR ${ }^{\mathrm{ER}}$ contributes to the pathogeneses in a number of pulmonary diseases in which AECs encounter frequent ER stress.

Author disclosures are available with the text of this article at www.atsjournals.org. 


\section{References}

1. Wang M, Kaufman RJ. Protein misfolding in the endoplasmic reticulum as a conduit to human disease. Nature 2016;529:326-335.

2. Walter $P$, Ron $D$. The unfolded protein response: from stress pathway to homeostatic regulation. Science 2011;334:1081-1086.

3. Clarke HJ, Chambers JE, Liniker E, Marciniak SJ. Endoplasmic reticulum stress in malignancy. Cancer Cell 2014;25:563-573.

4. Hetz C, Papa FR. The unfolded protein response and cell fate control. Mol Cell 2018;69:169-181.

5. Melber A, Haynes CM. UPR ${ }^{\mathrm{mt}}$ regulation and output: a stress response mediated by mitochondrial-nuclear communication. Cell Res 2018;28: 281-295.

6. Haynes CM, Petrova K, Benedetti C, Yang Y, Ron D. ClpP mediates activation of a mitochondrial unfolded protein response in $\mathrm{C}$. elegans. Dev Cell 2007;13:467-480.

7. Haynes CM, Ron D. The mitochondrial UPR: protecting organelle protein homeostasis. J Cell Sci 2010;123:3849-3855.

8. Nargund AM, Pellegrino MW, Fiorese CJ, Baker BM, Haynes CM. Mitochondrial import efficiency of ATFS-1 regulates mitochondrial UPR activation. Science 2012;337:587-590.

9. Fiorese CJ, Schulz AM, Lin YF, Rosin N, Pellegrino MW, Haynes CM. The transcription factor atf5 mediates a mammalian mitochondrial upr. Curr Biol 2016;26:2037-2043.

10. Quirós PM, Prado MA, Zamboni N, D’Amico D, Williams RW, Finley D, et al. Multi-omics analysis identifies ATF4 as a key regulator of the mitochondrial stress response in mammals. J Cell Biol 2017;216:2027-2045.

11. Horibe T, Hoogenraad NJ. The chop gene contains an element for the positive regulation of the mitochondrial unfolded protein response. PLoS One 2007;2:e835.

12. Smyrnias I, Gray SP, Okonko DO, Sawyer G, Zoccarato A, Catibog N, et al. Cardioprotective effect of the mitochondrial unfolded protein response during chronic pressure overload. J Am Coll Cardiol 2019; 73:1795-1806.

13. Mouchiroud L, Houtkooper RH, Moullan N, Katsyuba E, Ryu D, Cantó C, et al. The $\mathrm{nad}(+) /$ sirtuin pathway modulates longevity through activation of mitochondrial upr and foxo signaling. Cell 2013;154:430-441.

14. Pellegrino MW, Nargund AM, Kirienko NV, Gillis R, Fiorese CJ, Haynes CM. Mitochondrial UPR-regulated innate immunity provides resistance to pathogen infection. Nature 2014;516:414-417.

15. Mohrin M, Shin J, Liu Y, Brown K, Luo H, Xi Y, et al. Stem cell aging: a mitochondrial UPR-mediated metabolic checkpoint regulates hematopoietic stem cell aging. Science 2015;347:1374-1377.

16. Hunt RJ, Granat L, McElroy GS, Ranganathan R, Chandel NS, Bateman JM. Mitochondrial stress causes neuronal dysfunction via an ATF4dependent increase in L-2-hydroxyglutarate. J Cell Biol 2019;218: 4007-4016.

17. Yung HW, Colleoni F, Dommett E, Cindrova-Davies T, Kingdom J, Murray AJ, et al. Noncanonical mitochondrial unfolded protein response impairs placental oxidative phosphorylation in earlyonset preeclampsia. Proc Natl Acad Sci USA 2019;116:18109-18118.

18. Kropski JA, Blackwell TS. Endoplasmic reticulum stress in the pathogenesis of fibrotic disease. J Clin Invest 2018;128:64-73.

19. Mizumura K, Cloonan SM, Nakahira K, Bhashyam AR, Cervo M, Kitada T, et al. Mitophagy-dependent necroptosis contributes to the pathogenesis of COPD. J Clin Invest 2014;124:3987-4003.

20. Hassan T, Carroll TP, Buckley PG, Cummins R, O'Neill SJ, McElvaney $\mathrm{NG}$, et al. miR-199a-5p silencing regulates the unfolded protein response in chronic obstructive pulmonary disease and $\alpha 1$ antitrypsin deficiency. Am J Respir Crit Care Med 2014;189:263-273.

21. Lawson WE, Crossno PF, Polosukhin VV, Roldan J, Cheng DS, Lane $\mathrm{KB}$, et al. Endoplasmic reticulum stress in alveolar epithelial cells is prominent in IPF: association with altered surfactant protein processing and herpesvirus infection. Am J Physiol Lung Cell Mol Physiol 2008;294:L1119-L1126.

22. Tanjore H, Blackwell TS, Lawson WE. Emerging evidence for endoplasmic reticulum stress in the pathogenesis of idiopathic pulmonary fibrosis. Am J Physiol Lung Cell Mol Physiol 2012;302:L721-L729.

23. Li C, Weng Z, Doran SF, Srivastava RK, Afaq F, Matalon S, et al. Chlorine induces the unfolded protein response in murine lungs and skin. Am J Respir Cell Mol Biol 2013;49:197-203.
24. Shah D, Romero F, Guo Z, Sun J, Li J, Kallen CB, et al. Obesity-induced endoplasmic reticulum stress causes lung endothelial dysfunction and promotes acute lung injury. Am J Respir Cell Mol Biol 2017;57: 204-215.

25. Selman M, Pardo A. The leading role of epithelial cells in the pathogenesis of idiopathic pulmonary fibrosis. Cell Signal 2020;66:109482.

26. Cui H, Ge J, Xie N, Banerjee S, Zhou Y, Antony VB, et al. Mir-34a inhibits lung fibrosis by inducing lung fibroblast senescence. Am J Respir Cell Mol Biol 2017;56:168-178.

27. Cui H, Ge J, Xie N, Banerjee S, Zhou Y, Liu RM, et al. miR-34a promotes fibrosis in aged lungs by inducing alveolarepithelial dysfunctions. Am J Physiol Lung Cell Mol Physiol 2017;312:L415-L424.

28. Cui H, Xie N, Jiang D, Banerjee S, Ge J, Sanders YY, et al. Inhibition of glutaminase 1 attenuates experimental pulmonary fibrosis. Am J Respir Cell Mol Biol 2019;61:492-500.

29. Cui H, Banerjee S, Guo S, Xie N, Ge J, Jiang D, et al. Long noncoding RNA Malat1 regulates differential activation of macrophages and response to lung injury. JCI Insight 2019;4:e124522.

30. Bueno M, Lai YC, Romero Y, Brands J, St Croix CM, Kamga C, et al PINK1 deficiency impairs mitochondrial homeostasis and promotes lung fibrosis. J Clin Invest 2015;125:521-538.

31. Moore BB, Hogaboam CM. Murine models of pulmonary fibrosis. Am J Physiol Lung Cell Mol Physiol 2008;294:L152-L160.

32. Knupp J, Arvan P, Chang A. Increased mitochondrial respiration promotes survival from endoplasmic reticulum stress. Cell Death Differ 2019;26:487-501.

33. Bueno M, Brands J, Voltz L, Fiedler K, Mays B, St Croix C, et al. ATF3 represses PINK1 gene transcription in lung epithelial cells to control mitochondrial homeostasis. Aging Cell 2018;17:e12720.

34. Lebeau J, Saunders JM, Moraes VWR, Madhavan A, Madrazo N, Anthony $\mathrm{MC}$, et al. The perk arm of the unfolded protein response regulates mitochondrial morphology during acute endoplasmic reticulum stress. Cell Rep 2018;22:2827-2836.

35. Bouman L, Schlierf A, Lutz AK, Shan J, Deinlein A, Kast J, et al. Parkin is transcriptionally regulated by ATF4: evidence for an interconnection between mitochondrial stress and ER stress. Cell Death Differ 2011;18:769-782.

36. Tanjore H, Cheng DS, Degryse AL, Zoz DF, Abdolrasulnia R, Lawson WE, et al. Alveolar epithelial cells undergo epithelial-to-mesenchymal transition in response to endoplasmic reticulum stress. $J$ Biol Chem 2011;286:30972-30980.

37. Borok Z, Horie M, Flodby P, Wang H, Liu Y, Ganesh S, et al. Grp78 loss in epithelial progenitors reveals an age-linked role for endoplasmic reticulum stress in pulmonary fibrosis. Am J Respir Crit Care Med 2020;201:198-211.

38. Delbrel E, Uzunhan Y, Soumare A, Gille T, Marchant D, Planès C, et al. Er stress is involved in epithelial-to-mesenchymal transition of alveolar epithelial cells exposed to a hypoxic microenvironment. Int $J$ Mol Sci 2019;20:1299.

39. Cui H, Xie N, Banerjee S, Ge J, Guo S, Liu G. Impairment of fatty acid oxidation in alveolar epithelial cells mediates acute lung injury. Am J Respir Cell Mol Biol 2019;60:167-178.

40. Zhang S, Macias-Garcia A, Ulirsch JC, Velazquez J, Butty VL, Levine SS, et al. HRI coordinates translation necessary for protein homeostasis and mitochondrial function in erythropoiesis. eLife 2019;8:e46976.

41. Balsa E, Soustek MS, Thomas A, Cogliati S, García-Poyatos C, MartínGarcía E, et al. ER and nutrient stress promote assembly of respiratory chain supercomplexes through the PERK-elF2 $\alpha$ axis. Mol Cell 2019;74:877-890, e6.

42. Pakos-Zebrucka K, Koryga I, Mnich K, Ljujic M, Samali A, Gorman AM. The integrated stress response. EMBO Rep 2016;17:1374-1395.

43. Sharma K, Vu TT, Cook W, Naseri M, Zhan K, Nakajima W, et al. p53independent Noxa induction by cisplatin is regulated by ATF3/ATF4 in head and neck squamous cell carcinoma cells. Mol Oncol 2018; 12:788-798.

44. Wang YT, Lim Y, McCall MN, Huang KT, Haynes CM, Nehrke K, et al. Cardioprotection by the mitochondrial unfolded protein response requires ATF5. Am J Physiol Heart Circ Physiol 2019;317:H472-H478.

45. Shpilka T, Haynes CM. The mitochondrial UPR: mechanisms, physiological functions and implications in ageing. Nat Rev Mol Cell Biol 2018;19:109-120. 